\title{
Clinical Safety and Tolerability of Vildagliptin - Insights from Randomised Trials, Observational Studies and Post-marketing Surveillance
}

\author{
Chantal Mathieu, ${ }^{1}$ Plamen Kozlovski, ${ }^{2}$ Päivi M Paldánius, ${ }^{2}$ James E Foley, ${ }^{3}$ Vikas Modgill, ${ }^{2}$ Marc Evans ${ }^{4}$ and Carmen Serban ${ }^{2}$ \\ 1. Katholieke Universiteit Leuven, Leuven, Belgium; 2. Novartis Pharma AG, Basel, Switzerland; 3. Novartis Pharmaceuticals Corporation, East Hanover, \\ NJ, US; 4. Diabetes Resource Centre, Llandough Hospital, Cardiff, UK
}

$\mathrm{V}$ ildagliptin is one of the most extensively studied dipeptidyl peptidase-4 (DPP-4) inhibitors in terms of its clinical utility. Over the last decade, a vast panorama of evidence on the benefit-risk profile of vildagliptin has been generated in patients with type 2 diabetes mellitus (T2DM). In this article, we review the cumulative evidence on the safety of vildagliptin from the clinical development programme, as well as reports of rare adverse drug reactions detected during the post-marketing surveillance of the drug. Across clinical studies, the overall safety and tolerability profile of vildagliptin was similar to placebo, and it was supported by real-world data in a broad population of patients with T2DM, making DPP-4 inhibitors, like vildagliptin, a safe option for managing patients with T2DM.

\section{Keywords}

Dipeptidyl peptidase-4 (DPP-4) inhibitors, post-

marketing surveillance, safety, vildagliptin

Disclosure: Chantal Mathieu serves or has served on the advisory panel for AstraZeneca, Boehringer Ingelheim, Bristol-Myers Squibb, Eli Lilly and Company, Intrexon, Janssen Pharmaceuticals, Hanmi Pharmaceuticals, Mannkind, Medtronic, Merck Sharp \& Dohme Corp., Novartis, Novo Nordisk, Pfizer, Sanofi, Roche Diagnostics and UCB. Chantal Mathieu serves or has served on the speaker's bureau for AstraZeneca, Boehringer Ingelheim, Eli Lilly and Company, Merck Sharp \& Dohme Corp., Novartis, Novo Nordisk and Sanofi. Katholieke Universiteit Leuven has received research support for Chantal Mathieu from Abbott, Eli Lilly and Company, Intrexon, Merck Sharp \& Dohme Corp., Novartis, Novo Nordisk, Roche Diagnostics and Sanofi. Plamen Kozlovski, Päivi M Paldánius, Vikas Modgill and Carmen Serban are employees and shareholders of Novartis Pharma AG. James E Foley is an employee and shareholder of Novartis Pharmaceuticals Corporation. Marc Evans received financial support for consulting from Novartis, Merck Sharp \& Dohme Corp. and Novo Nordisk and has served on speaker's bureau for Novartis, Eli Lilly, Boehringer Ingelheim, Merck Sharp \& Dohme Corp., Novo Nordisk, Janssen and Takeda. Acknowledgements: Medical writing assistance was provided by Amit Kumar Garg and Lakshmi Deepa of Novartis Healthcare Private Limited, Hyderabad, India. Compliance with Ethics: This study involves a review of the literature and did not involve any studies with human or animal subjects performed by any of the authors. Authorship: All named authors meet the International Committee of Medical Journal Editors (ICMJE) criteria for authorship of this manuscript, take responsibility for the integrity of the work as a whole, and have given final approval to the version to be published.

open Access: This article is published under the Creative Commons Attribution Noncommercial License, which permits any non-

commercial use, distribution, adaptation and reproduction provided

the original author(s) and source are given appropriate credit.

Received: 26 May 2017

Accepted: 25 July 2017

Citation: European Endocrinology, 2017;13(2):68-72

Corresponding Author: Chantal Mathieu, Department of Clinical and Experimental Medicine, Katholieke Universiteit Leuven, UZ Herestraat 49, Leuven 3000, Belgium. E: chantal.mathieu@uz.kuleuven.ac.be

Support: The publication of this article was supported by Novartis Pharma AG.
The introduction of vildagliptin, a dipeptidyl peptidase-4 (DPP-4) inhibitor, for the treatment of type 2 diabetes mellitus (T2DM) in 2007 provided clinicians with a novel and effective treatment option for lowering blood glucose, which neither caused weight gain nor increased the risk of hypoglycaemia. ${ }^{1,2}$ However, looking back on early development, there were theoretical apprehensions regarding the overall benefit-risk profile of DPP-4 inhibitors as anti-diabetes agents, due to the involvement of DPP-4 in the metabolism of other bioactive peptides. ${ }^{3}$ Being the first molecules under development, extensive in vitro and pre-clinical studies were conducted with vildagliptin and its predecessor, DPP-728, to map their off-target pharmacology. The in vitro and pre-clinical safety profiles were encouraging, with only a few species-specific safety signals pertaining to the gastrointestinal, cardiovascular (CV) and immune systems at concentrations that were approximately five to seven times the anticipated human exposure. ${ }^{4,5}$ These insights from the pre-clinical studies were taken into account while designing the clinical development programme, and a special feature was the prospective, independent adjudication of $\mathrm{CV}$ events enabling a proper meta-analysis to establish the CV safety of vildagliptin at programme completion.

The benefit-risk profile of a new agent is seldom complete at the time of launch, as limited exposure in randomised controlled trials (RCTS) does not provide adequate evidence regarding the safety of the agent under real-world conditions. ${ }^{6.7}$ It is therefore important to continuously monitor the safety of any therapeutic agent post-launch using a variety of complementary approaches. The concept of risk management, although used empirically, was formally introduced for all new medical entities in Europe in 2006. ${ }^{8}$ This coincided with the time when the first DPP-4 inhibitors were approved. The main focus of a risk management plan (RMP) is to identify and minimise the risks associated with the drug. The use of RMPs, along with an increased emphasis on CV safety 10 led to the enrichment of the drug development programmes in diabetes, involving pooled safety analyses, meta-analyses and, when required, large, randomised, controlled outcome trials. These modalities, along with the real-world studies, paint the full picture of the safety, tolerability, and effectiveness of this class. 
Vildagliptin, one of the earlier launched DPP-4 inhibitors, ${ }^{11}$ is marketed in over 125 countries, and more than 17 million patients have been exposed to vildagliptin since its launch in 2007. This article reviews the overall safety and tolerability profile of vildagliptin, with a focus on adverse events (AES) that have been of interest for patients with T2DM or for the DPP-4 inhibitor class in general. In addition to the pre-clinical data generated over the last decades, this article includes data from the latest vildagliptin CV meta-analysis, ${ }^{12}$ observational studies, ${ }^{13}$ findings from post-marketing surveillance (PMS) reported to the health authorities and the most recent cumulative safety analysis part of the periodic safety update report. The latter includes 58 phase II to IV Novartis-sponsored RCTs comprising more than 10,000 patients treated with vildagliptin $50 \mathrm{mg}$ (once daily [ad]/ twice daily [bid]) and more than 8,000 patients treated with comparators (placebo and active comparators). AEs in all the studies were assessed by the investigator and were encoded using the MedDRA system. Mantel-Haenszel risk ratios (MHRR) were used to compare selected AEs between vildagliptin and comparators. The methodology for pooling and analysis is similar to that reported in the earlier pooled safety publications, ${ }^{14,15}$ and results are expressed as exposure-adjusted incidence, i.e., number of patients having event over 100 subject-years of exposure (SYES).

\section{General safety and tolerability}

Upon oral administration, vildagliptin is rapidly absorbed and is primarily eliminated by hydrolysis via multiple organs/tissues. ${ }^{16}$ The diverse, noncytochrome P450 (CYP)-mediated metabolic pathways and negligible protein binding $(<10 \%)$ indicate a low potential for drug interactions for vildagliptin. ${ }^{16}$ This was further confirmed in the drug interaction studies with commonly co-prescribed medications (metformin, pioglitazone, glyburide, simvastatin, amlodipine, valsartan, ramipril, digoxin and warfarin), which did not indicate any clinically relevant changes in the pharmacokinetics (PK) of any of the administered drugs. ${ }^{17}$ Furthermore, the PK of vildagliptin is not affected by age, gender, body mass index, food or ethnicity. ${ }^{18}$

A wealth of evidence from RCTs and real-world studies has consistently demonstrated that vildagliptin is an effective and well-tolerated treatment, with an established weight neutrality and low risk of hypoglycaemia. ${ }^{19,20}$ A pooled safety analysis of 58 trials (vildagliptin, $n=10,331 ; 9,602$ SYES; all comparators, $n=8,068 ; 7,386$ SYES) has shown that the frequency of overall AES $(64.5 \%$ versus $66.0 \%$ for vildagliptin versus all comparators, respectively), serious adverse events (SAEs; $8.0 \%$ versus $8.5 \%$, respectively), discontinuations (5.2\% versus $5.8 \%$, respectively) and deaths ( $0.5 \%$ in both the groups) was similar between vildagliptin and all comparators. There was no specific trend in the $A E$ and SAE profiles and the events were distributed across many different system organ classes (SOC). Similarly, no major imbalances were found between vildagliptin and comparators in the frequency of AEs leading to discontinuations. These findings are also supported by the large, reallife, Effectiveness of Diabetes control with vildaGliptin and vildagliptin/ mEtformin (EDGE) study ( $n=45868$ ), in which the incidence of overall AEs was similar in the vildagliptin (5.3\%) and comparator groups (5.7\%). ${ }^{13}$ Further evidence comes from a systematic review and meta-analysis, which concluded that vildagliptin is a safe therapeutic option for patients with T2DM, both as monotherapy and as add-on treatment. ${ }^{19}$ Vildagliptin is approved for use as monotherapy and in combination with other anti-hyperglycaemic agents. It is also indicated for special populations (elderly, renal impairment) and there are no contraindications beyond hypersensitivity to the active constituent. ${ }^{5}$ Overall, the evidence from RCTs and real-world studies provides reassurance regarding the general safety of vildagliptin in a broad population of patients with T2DM. ${ }^{2}$

\section{Adverse events of special interest for dipeptidyl peptidase- 4 inhibition-based therapies Immune related and infections}

DPP-4, also known as CD26, plays an essential role in immune response as it is extensively expressed on T-lymphocytes. ${ }^{22}$ The DPP-4 catalytic site is a small part of CD26, and in vitro studies have shown that binding to the catalytic site does not affect binding on other sites of CD26. concerted efforts were made in both early pre-clinical and clinical studies to identify any potential effects of vildagliptin on the immune system. In rats, vildagliptin was well tolerated at a daily dose of up to $900 \mathrm{mg} / \mathrm{kg}$, and both primary and secondary immunoglobulin responses were not affected. Other animal studies have also confirmed that vildagliptin does not impair key parameters of the innate and adaptive immune responses. ${ }^{23}$

Similarly, data from clinical trials did not indicate an increased risk of infections, even in the most vulnerable subjects, such as very elderly or those with renal impairment. ${ }^{24,25}$ In the pooled safety analysis, the overall exposure-adjusted incidence of AES in the infections and infestations SOC was comparable between vildagliptin (33.1/100 SYES) and all comparators (32.9/100 SYES), and the incidence of SAES in the same SOC was $1.5 / 100$ SYEs in both the groups. Furthermore, in a comprehensive systematic review and meta-analysis, no increase in nasopharyngitis (odds ratio [OR] 1.06; 95\% confidence interval [Cl] 0.93-1.21), upper respiratory tract infections (OR 1.19; $95 \% \mathrm{Cl}$ 0.98-1.45) or urinary tract infections (OR 0.94; 95\% Cl 0.57-1.56) was reported with vildagliptin. ${ }^{19}$

\section{Angioedema}

Potential interaction between DPP-4 inhibitors and angiotensinconverting enzyme (ACE) inhibitors has been studied, as both DPP-4 and ACE are actively involved in the metabolism of substance P. ${ }^{26}$ To address this, all the angioedema-related AEs in the vildagliptin clinical trial programme were independently and prospectively adjudicated. In the updated vildagliptin pooled safety analysis, the incidence of angioedema was similar between vildagliptin and all comparators $(0.3 \%$ in both the groups). However, there were more events of angioedema in patients taking vildagliptin concurrently with an ACE inhibitor $(0.5 \%)$ when compared to comparators $(0.3 \%)$. The majority of the angioedema cases were mild and resolved with ongoing treatment. Similar findings were also observed with other DPP-4 inhibitors. ${ }^{27-29}$

\section{Acute pancreatitis}

Patients with T2DM have a twofold increased risk of acute pancreatitis compared with healthy individuals. ${ }^{30}$ Vildagliptin, as all incretin-based therapies, has been extensively evaluated for its pancreatic safety in various pre-clinical and pooled analyses, due to the potential risk of pancreatic events with glucagon like peptide-1 (GLP-1) based therapies, despite the lack of evidence of a causal relationship. Long-term studies in rodents (rats and mice) at approximately 200 times the human exposure dose have shown that vildagliptin is not associated with any evidence of pancreatitis. ${ }^{31}$ Similar findings have been observed for all the other GLP-1 based therapies. ${ }^{32}$ The pooled safety analysis of data from all phase II-IV studies demonstrated that the incidence of acute pancreatitis was similar for vildagliptin and all comparators (0.3/100 SYEs in both the groups). This was further confirmed by a meta-analysis of 69 trials, wherein there was no increased risk of pancreatitis with vildagliptin relative to comparators (OR 0.97; 95\% Cl 0.37-2.53; $\left.\right|^{2}=0 \%$ ). ${ }^{19}$

Post-marketing cases of pancreatic AEs have been reported with the use of various anti-diabetes agents over time, including GLP-1 based 
Figure 1: Incidence and risk ratios for adjudicated composite endpoint of major adverse cardiovascular events and its individual components with vildagliptin (50 mg once daily/twice daily) versus comparators (placebo and active comparators)

\begin{tabular}{|c|c|c|c|c|c|}
\hline & $\begin{array}{l}\text { Vildagliptin } \\
\text { n/N (\%) }\end{array}$ & $\begin{array}{c}\text { Comparators } \\
\mathrm{n} / \mathrm{N}(\%)\end{array}$ & $\begin{array}{r}\text { MHRR } \\
(95 \% \mathrm{Cl})\end{array}$ & & \\
\hline $\begin{array}{r}\text { MACE Composite } \\
\text { Endpoint }\end{array}$ & $\begin{array}{c}83 / 9,599 \\
(0.86)\end{array}$ & $\begin{array}{c}85 / 7,102 \\
(1.20)\end{array}$ & $\begin{array}{c}0.82 \\
(0.61-1.11)\end{array}$ & rot & \\
\hline $\begin{array}{l}\text { Myocardial } \\
\text { Infarction }\end{array}$ & $\begin{array}{c}38 / 9,599 \\
(0.40)\end{array}$ & $\begin{array}{c}35 / 7,102 \\
(0.49)\end{array}$ & $\begin{array}{c}0.87 \\
(0.56-1.38)\end{array}$ & & \\
\hline Stroke & $\begin{array}{c}24 / 9,599 \\
(0.25)\end{array}$ & $\begin{array}{c}25 / 7,102 \\
(0.35)\end{array}$ & $\begin{array}{c}0.84 \\
(0.47-1.50)\end{array}$ & & \\
\hline \multirow[t]{3}{*}{ CV Death } & $\begin{array}{c}25 / 9,599 \\
(0.26)\end{array}$ & $\begin{array}{c}28 / 7,102 \\
(0.39)\end{array}$ & $\begin{array}{c}0.77 \\
(0.45-1.31)\end{array}$ & $\mapsto-1$ & \\
\hline & & & $0.01 \quad 0.1$ & 1.0 & $10.0 \quad 100.0$ \\
\hline & & & $\begin{array}{r}\text { Vildaglip } \\
\text { Better }\end{array}$ & & $\begin{array}{l}\text { Comparator } \\
\text { Better }\end{array}$ \\
\hline
\end{tabular}

$\mathrm{Cl}=$ confidence interval; $\mathrm{CV}=$ cardiovascular; $\mathrm{MACE}=$ major adverse $\mathrm{CV}$ events consisting of myocardial infarction, stroke and CV death; MHRR = Mantel-Haenszel risk ratio.

therapies. ${ }^{33}$ Although an extensive evaluation of non-clinical and clinical data by the European Medicines Agency (EMA) and the US Food and Drug Administration (FDA) suggested no causal association between pancreatic AEs and GLP-1 based therapies, ${ }^{34}$ the risk of acute pancreatitis has been added to the label of all the GLP-1 based therapies. A recent meta-analysis using data from the CV outcomes trials for pooled DPP4 inhibitors (excluding vildagliptin) demonstrated an increased relative risk of acute pancreatitis (OR 1.79; 95\% Cl 1.13-2.82) $)^{35}$ versus placebo, albeit the absolute risk increase was low $(0.13 \%)^{35}$

\section{Adverse events of special interest for patients with T2DM \\ Neoplasms}

There is evidence indicating an increased risk of cancer in patients with T2DM. ${ }^{36}$ Vildagliptin has been evaluated in a range of genotoxicity assays, the results of which did not indicate a genotoxic risk to humans. A 2-year carcinogenicity study in rats, with a dose approximately 200 times the human exposure, did not show an increase in overall tumour incidence. ${ }^{5}$ In another study in mice at a dose $>240$ times the human exposure, a slight increase in the incidence of mammary adenocarcinomas was observed with vildagliptin, the no-effect dose being approximately $500 \mathrm{mg} / \mathrm{kg}$ (59-fold human exposure). In the vildagliptin pooled safety analysis, the incidence of all cancers (benign, malignant, and unspecified neoplasms) was similar with vildagliptin and comparators (1.9\% in both the groups). There was a numerical imbalance in the incidence of the AE of breast cancer, 0.4 versus $0.2 / 100$ SYES (vildagliptin versus all comparators); however, the incidence in the all-comparator group was lower than the previously reported incidence of breast cancer from largescale epidemiological studies, ${ }^{37,38}$ which suggests that the imbalance might be a chance finding.

The development of drug-induced carcinogenicity takes a long time, so exposure during RCTs is unlikely to uncover such risks. ${ }^{39}$ Using evidence from RCTs and open-label safety studies, the incidence of neoplasms of interest for incretin-based therapies, such as pancreatic cancer, appeared to be lower with vildagliptin than comparators ( 0.026 versus $0.04 / 100$ SYES). It is reassuring that more than 10 years of PMS by health authorities and pharmaceutical companies did not suggest an increased risk of cancer with DPP-4 inhibitor therapy.

\section{Cardiovascular safety}

DPP-4 inhibitors have been extensively evaluated for their CV safety, and the cumulative evidence has demonstrated $\mathrm{CV}$ safety with respect to major adverse CV events (MACE). However, as increased rates of hospitalisation for heart failure (HF) were observed with saxagliptin (saxagliptin, 3.5\% versus placebo, 2.8\%; hazard ratio [HR] 1.27; 95\% Cl $1.07-1.51 ; \mathrm{p}=0.007){ }^{40}$ and alogliptin (3.1\% versus placebo, $2.9 \%$; HR 1.07; $95 \% \mathrm{Cl}$ 0.79-1.46), ${ }^{41}$ the FDA (5 April 2016) requested for inclusion of the potential increased risk of HF to the labels of saxagliptin and alogliptin. ${ }^{42}$ A large, real-world observational study in more than 127,000 patients demonstrated a lower risk for HF-related hospitalisations in DPP-4 inhibitor-treated patients versus sulphonylureas. ${ }^{43,44}$

Analysis of patient-level data pooled from large development programmes, which provide sufficient exposure to the investigational drug and include diverse patient populations and comparators, is a robust way of assessing CV safety. ${ }^{9}$ The CV safety of vildagliptin was confirmed in a meta-analysis of independently and prospectively adjudicated CV events from 40 phase III and IV trials enrolling over 17,000 patients. The MHRR for the incidence of MACE with vildagliptin versus comparator was $0.82(95 \% \mathrm{Cl} 0.61-1.11)$. Similar risk ratios (RRS) were observed for the individual MACE endpoints: myocardial infarction $(0.87 ; 95 \% \mathrm{Cl} 0.56-1.38)$, stroke $(0.84 ; 95 \% \mathrm{Cl} 0.47-1.50)$ and CV death $(0.77 ; 95 \% \mathrm{Cl} 0.45-1.131)$ (see Figure 1). The meta-analysis also included patients with advanced disease (T2DM duration more than 10 years), elderly (over 65 years of age), patients with renal impairment and patients with congestive heart failure (CHF). ${ }^{12}$ As the events were prospectively adjudicated, and the upper bound of the $95 \% \mathrm{Cl}$ was $<1.3$, an additional outcome trial was not required to establish the $\mathrm{CV}$ safety of vildagliptin. ${ }^{45}$

In the CV meta-analysis, the MHRR for the incidence of confirmed HF events (vildagliptin versus comparator) was 1.08 (95\% Cl 0.68-1.70), showing no increased risk of HF in vildagliptin-treated patients versus comparators. ${ }^{12}$ The safety of vildagliptin in patients with CHF (New York Heart Association [NYHA] class I-III) was also assessed in the 52-week, double-blind, randomised, Vildagliptin In Ventrlcular Dysfunction Diabetes (VIVIDD) trial, which showed that vildagliptin was not associated with a change in left ventricular function or worsening of pre-existing $\mathrm{CHF}^{46} \mathrm{An}$ analytical, non-interventional, multi-database study provided further evidence on the relative safety of vildagliptin in CHF under real-life conditions. ${ }^{47}$ The adjusted incidence risk ratios (IRRS) for CHF were close to 1 (0.49-1.03) forvildagliptin versus other non-insulin antidiabetic medications. ${ }^{47}$

\section{Hepatic safety}

It is important to establish the hepatic safety of an anti-diabetes agent as patients with T2DM have a high prevalence of liver disease compared to the general population. ${ }^{48}$ Evidence from non-clinical toxicology and in vitro studies did not indicate a risk of hepatotoxicity with vildagliptin. Since vildagliptin is not metabolised by CYP to a significant extent, the presence of hepatic impairment does not increase the exposure to vildagliptin. ${ }^{9}$

In the pooled safety analysis, the incidence of mild elevations in hepatic enzymes (alanine aminotransferase [ALT] and aspartate aminotransferase [AST] $\geq 3$ times upper limit of normal [ULN]) was similar for vildagliptin versus comparators (MHRR 1.19; 95\% Cl 0.79-1.81), and there was no increased risk for ALT and AST $\geq 3$ ULN, accompanied by bilirubin >ULN (MHRR 0.97; 95\% Cl 0.16-5.92). The incidence of hepatic AEs (1.6 versus $1.8 / 100$ SYES, respectively) and SAES ( 0.2 versus $0.1 / 100$ 
SYES, respectively) was similar between the vildagliptin and comparator groups. In the large, observational EDGE study, liver function test (LFT) abnormalities were infrequent: in the vildagliptin group, 411 of 9,508 patients (4.3\%) had bilirubin >ULN versus 190 of 4,691 patients (4.1\%) receiving other oral anti-diabetes drugs (OADs). ${ }^{13}$ However, a study in patients with T2DM having good glycaemic control (glycated haemoglobin $[\mathrm{HbA} 1 \mathrm{C}] \leq 7.9 \%$ ) demonstrated that treatment with vildagliptin results in a clinically meaningful decrease in liver triglyceride levels, which was associated with a decrease in plasma ALT and glucose levels. ${ }^{50}$ Rare cases of elevations in hepatic enzymes that were generally asymptomatic without clinical sequelae have been observed. ${ }^{5}$ Vildagliptin is not recommended in patients with hepatic impairment, including patients with elevated ALT/AST levels.

\section{Renal safety}

The renal safety profile of an anti-diabetes agent is yet another important consideration, as chronic kidney disease is a common late-stage complication of progressive T2DM. The increased risk of hypoglycaemia and increased or unpredictable exposure to, not only anti-diabetes, but also other drugs adds to the complexity of managing T2DM in patients with renal impairment. The benefit-risk profile of vildagliptin has been extensively evaluated in patients with renal impairment in studies ranging from PK assessment ${ }^{51}$ to clinical safety in patients undergoing haemodialysis. ${ }^{52}$ In subjects with moderate or severe renal impairment, the exposure to vildagliptin increases up to twofold, without significantly affecting the maximum concentration (Cmax); accordingly, the effective half-life is increased sufficiently to allow a $50 \mathrm{mg}$ qd dose in patients with moderate to severe renal impairment. ${ }^{51}$

The efficacy and safety of vildagliptin in patients with moderate or severe renal impairment were evaluated in a large $(n=525)$ 1-year randomised trial. The safety profile of vildagliptin $50 \mathrm{mg}$ qd in patients with moderate or severe renal impairment was similar to that of placebo. ${ }^{25}$ In another study, vildagliptin and sitagliptin $(n=148)$ showed similar safety profiles in patients with severe renal impairment. ${ }^{53}$ There is no evidence that failure to adjust for an increase in exposure with vildagliptin results in renal toxicity. ${ }^{54}$ Vildagliptin was well tolerated in patients with severe renal impairment uncontrolled on insulin, 55 in elderly patients ( $\geq 75$ years) with moderate or severe renal impairment, ${ }^{56}$ in patients with new-onset diabetes after transplantation (NODAT $)^{57}$ and in patients undergoing haemodialysis, ${ }^{52}$ with a similar AE/SAE profile to placebo.

\section{Additional adverse drug reactions from post-marketing experience}

Although the assessment of safety using data from controlled studies remains the gold standard, it is important to assess PMS reports in order to continuously evaluate the benefit-risk profile of a drug. Furthermore, as PMS reports contain data from a large number of diverse patients, certain rare AEs that are otherwise not observed during the clinical trial programme, may appear over time. Such events are rare and by virtue of being detected retrospectively, their association with the drug is not conclusively established, as findings are often complicated by co-medications and comorbidities. some events such as acute pancreatitis and hepatobiliary disorders have been discussed earlier; in addition, other adverse reactions emerging from PMS include skin-related events and musculoskeletal disorders (arthralgia).

\section{Skin-related adverse events}

Patients with T2DM have an increased risk of skin-related diseases. Skin lesions in extremities of Cynomolgus monkeys were observed with vildagliptin during early pre-clinical studies at doses of $\geq 5 \mathrm{mg} / \mathrm{kg} /$ day. ${ }^{4}$ The lesions were of vascular origin and were not observed in any other animal species. ${ }^{4}$ Similarly, the vildagliptin pooled safety analysis did not find an increased incidence of all skin-related AEs with vildagliptin compared to comparators (1.6 versus $1.4 / 100$ SYEs, respectively); however, data from the recently published signal detection studies using pharmacovigilance databases showed increased reports of bullous pemphigoid (BP) in patients using DPP-4 inhibitors. ${ }^{58,59}$ The majority of bullous skin lesions were observed in elderly patients, ${ }^{60}$ which is consistent with the epidemiology data suggesting increasing age as a risk factor for $\mathrm{BP}^{61-63}$ In accordance with the guidance on routine care, monitoring for skin lesions in patients with T2DM treated with a DPP-4 inhibitor is recommended. ${ }^{5}$

\section{Arthralgia}

A warning of arthralgia/severe joint pain has been added to the labels of DPP-4 inhibitors ${ }^{64}$ on the basis of 33 rare cases of arthralgia/severe joint pain that were observed in a review of the FDA Adverse Event Reporting System database. ${ }^{65}$ In the pooled safety analysis, the incidence of arthralgia of any severity was similar for vildagliptin and comparators (3.7\% versus 3.3\%, respectively). One report suggests a slight increase in the incidence of arthralgia with vildagliptin (OR 1.23; 95\% Cl 1.02-1.48; $\left.\mathrm{l}^{2}=0 \% ; p=0.8\right){ }^{19}$

\section{Conclusions}

The efficacy profile, together with a low risk of hypoglycaemia, no weight gain, and absence of increased risk for $\mathrm{CV}$ events has established the clinical utility of DPP-4 inhibitors, such as vildagliptin, as anti-diabetes agents for the treatment of patients with T2DM. DPP-4 inhibitors as a class are also the most extensively evaluated oral glucose-lowering agents in terms of their benefit-risk profile which has contributed greatly to evidence-based clinical practice.

The cumulative clinical experience with vildagliptin and DPP-4 inhibitors, in general, has been encouraging in terms of their safety profile. Notably, vildagliptin did not increase the risk of any AEs of interest, such as infections, or those frequently observed in patients with T2DM, such as major adverse CV events. The key known risks include rare cases of mild to moderate elevations in hepatic enzymes, rare cases of angioedema (mostly in patients taking a concomitant ACE inhibitor) that resolved with ongoing treatment and acute pancreatitis, common for the GLP-1 based therapies. The data suggest that these AEs usually resolve upon drug discontinuation. The benefit-risk profile of vildagliptin has not changed considerably over the past 10 years, while the product has been widely used in clinical settings, with only a few reports of rare adverse drug reactions, including pancreatitis, bullous or exfoliative skin lesions and arthralgia, detected by PMS. By virtue of its established safety profile, vildagliptin continues to be a key treatment option for managing diverse patients with T2DM. $\square$ 
1. Ahren B, Simonsson E, Larsson $\mathrm{H}$, et al., Inhibition of dipeptidyl peptidase IV improves metabolic control over a 4-week study period in type 2 diabetes, Diabetes Care, 2002;25:869-75.

2. Ahren B, Vildagliptin: an inhibitor of dipeptidyl peptidasewith antidiabetic properties, Expert Opin Investig Drugs, 2006;15:431-42.

3. Mentlein R, Dipeptidyl-peptidase IV (CD26)-role in the inactivation of regulatory peptides, Regul Pept, 1999:85:9-24.

4. Hoffmann P, Bentley P, Sahota P, et al., Vascular origin of vildagliptin-induced skin effects in Cynomolgus monkeys: pathomechanistic role of peripheral sympathetic system and neuropeptide Y, Toxicol Pathol, 2014;42:684-95.

5. Galvus $50 \mathrm{mg}$ tablets-Summary of Product Characteristics (SMPC) . Available at: www.ema.europa.eu/docs/ en_GB/document_library/EPAR_-_Product_Information/ human/000771/WC500020327.pdf (accessed 16 April 2017).

6. CrickX E, Marroun I, Veyrie C, et al., DPP4 inhibitor-induced polyarthritis: a report of three cases, Rheumatol Int 2014;34:291-2.

7. Nauck MA, A critical analysis of the clinical use of incretinbased therapies: The benefits by far outweigh the potentia risks, Diabetes Care, 2013;36:2126-32.

8. European Medicines Agency: EMEA/192632/2006 - Postauthorisation Evaluation of Medicines for Human Use. Available at: www.ema.europa.eu/docs/en_GB/document_library/ Template_or form/2009/10/WC500006317.pdf (accessed 4 April 2017)

9. European Medicines Agency. Concept paper on the need for revision of the note for guidance on clinical investigation of medicinal products in the treatment of diabetes mellitus. Available at: www.ema.europa.eu/docs/en_GB/document_ library/Scientific_guideline/2009/09/WC500003182.pdf (accessed 16 April 2017)

10. US Food and Drug Administration. Center for Drug Evaluation and Research. Guidance for industry: diabetes mellitusevaluating cardiovascular risk in new antidiabetic therapies to treat type 2 diabetes. Available at: www.fda.gov/downloads/ Drugs/.../Guidances/ucm071627.pdf (accessed 16 April 2017).

11. Ahren B, Dipeptidyl peptidase-4 inhibitors: clinical data and clinical implications, Diabetes Care, 2007:30:1344-50.

12. McInnes G, Evans M, Del Prato S, et al., Cardiovascular and heart failure safety profile of vildagliptin: a meta-analysis of 17 000 patients, Diabetes Obes Metab, 2015;17:1085-92.

13. Mathieu C, Barnett AH, Brath $\mathrm{H}$, et al., Effectiveness and tolerability of second-line therapy with vildagliptin vs. other ora agents in type 2 diabetes: a real-life worldwide observational study (EDGE), Int J Clin Pract, 2013;67:947-56.

14. Ligueros-Saylan M, Foley JE, Schweizer A, Couturier A, Kothny W, An assessment of adverse effects of vildagliptin versus comparators on the liver, the pancreas, the immune system, the skin and in patients with impaired renal function from a Iarge pooled database of Phase II and III clinical trials, Diabetes Obes Metab, 2010;12:495-509.

15. Schweizer A, Dejager S, Foley JE, Kothny W, Assessing the general safety and tolerability of vildagliptin: value of pooled analyses from a large safety database versus evaluation of individual studies, Vasc Health Risk Manag, 2011;7:49-57.

16. He YL, Serra D, Wang Y, et al., Pharmacokinetics and pharmacodynamics of vildagliptin in patients with type 2 diabetes mellitus, Clin Pharmacokinet, 2007;46:577-88.

17. He YL, Clinical pharmacokinetics and pharmacodynamics of vildagliptin, Clin Pharmacokinet, 2012;51:147-62.

18. He YL, Sabo R, Campestrini J, et al., The effect of age, gender, and body mass index on the pharmacokinetics and pharmacodynamics of vildagliptin in healthy volunteers, Br J Clin Pharmacol, 2008;65:338-46.

19. Bekiari E, Rizava C, Athanasiadou E, et al., Systematic review and meta-analysis of vildagliptin for treatment of type 2 diabetes, Endocrine, 2016;52:458-80.

20. Keating GM, Vildagliptin: a review of its use in type 2 diabetes mellitus, Drugs, 2014;74:587-610.

21. SmPC V, Available at: http://wwwemaeuropaeu/docs/ en_GB/document_library/EPAR__Product_Information/ human/000771/WC500020327pdf (accessed 8 August 2017).

2. Yazbeck R, Howarth GS, Abbott CA, Dipeptidyl peptidas inhibitors, an emerging drug class for inflammatory disease? Trends Pharmacol SCi, 2009;30:600-7.

23. Anz D, Kruger S, Haubner S, et al., The dipeptidylpeptidase-IV inhibitors sitagliptin, vildagliptin and saxagliptin do not impair innate and adaptive immune responses, Diabetes Obes Metab,
2014;16:569-72.

24. Strain WD, Lukashevich V, Kothny W, et al., Individualised treatment targets for elderly patients with type 2 diabetes using vildagliptin add-on or lone therapy (INTERVAL): a 24 week, randomised, double-blind, placebo-controlled study, Lancet, 2013;382:409-16

25. Kothny W Shao Q Groop PH, Lukashevich V One-year safety, tolerability and efficacy of vildagliptin in patients with type 2 diabetes and moderate or severe renal impairment, Diabetes Obes Metab, 2012;14:1032-9.

26. Lefebvre J, Murphey $\amalg$, Hartert TV, et al., Dipeptidyl peptidase IV activity in patients with ACE-inhibitor-associated angioedema, Hypertension, 2002;39:460-4.

27. Onglyza $2.5 \mathrm{mg}$ tablets-Summary of Product Characteristics (SMPC). Available at: www.ema.europa.eu/docs/ en_GB/document_library/EPAR_-_Product_Information/ human/001039/WC500044316.pdf (accessed 16 April 2017).

28. Januvia $25 \mathrm{mg}$ tablets-Summary of Product Characteristics (SmPC). Available at: www.ema.europa.eu/docs/ en_GB/document_library/EPAR__Product_Information/ human/000722/WC500039054.pdf. (accessed 16 April 2017).

29. Vipidia $6.25 \mathrm{mg}$ tablets-Summary of Product Characteristics (SmPC). Available at: www.ema.europa.eu/docs/ en_GB/document_library/EPAR_-_Product_Information/ human/002182/WC500152271. pdf (accessed 16 April 2017).

30. Girman CJ, Kou TD, Cai B, et al., Patients with type 2 diabetes mellitus have higher risk for acute pancreatitis compared with those without diabetes, Diabetes Obes Metab, 2010;12:766-71

31. Busch SJ, Hoffmann P, Sahota P, et al., Studies in rodents with the dipeptidyl peptidase-4 inhibitor vildagliptin to evaluate possible drug-induced pancreatic histological changes that are predictive of pancreatitis and cancer development in man Diabetes Obes Metab, 2013;15:72-6.

32. European Medicines Agency. Assessment report for GLP-1 based therapies. July 25,2013 Available at: wnw.ema. europa eu/docs/en GB/document library/Report/2013/08/ WC500147026.pdf (accessed 16 April 2017)

33. Faillie UL Babai $S$, Crepin $S$, et al , Pancreatitis associated with the use of GLP-1 analogs and DPP-4 inhibitors: a case/ non-case study from the French Pharmacovigilance Database Acta Diabetol, 2014:51:491-7.

34. Egan AG, Blind E, Dunder $K$, et al., Pancreatic safety of incretin-based drugs-FDA and EMA assessment, N Eng/ I Med, 2014;370:794-7.

35. Tkac I, Raz I, Combined analysis of three large intervention trials with gliptins indicates increased incidence of acute pancreatitis in patients with type 2 diabetes, Diabetes Care 2017;40:284-6

36. Johnson JA, Carstensen B, Witte D, et al., Diabetes and cancer (1): evaluating the temporal relationship between type 2 diabetes and cancer incidence, Diabetologia, 2012;55:1607-18.

37. Michels KB, Solomon CG, Hu FB, et al., Type 2 diabetes and subsequent incidence of breast cancer in the Nurses' Health Study Diabetes Care, 2003:26:1752-8

38. Mink PJ Shahar E, Rosamond WD,et al Serum insulin and glucose levels and breast cancer incidence: the atherosclerosis risk in communities study, Am J Epidemiol, 2002;156:349-52.

39. Nadler DL, Zurbenko IG, Estimating cancer latency times using a weibull model, Advances in Epidemiology, 2014;2014:8

40. Scirica BM, Braunwald E, Raz I, et al., Heart failure, saxagliptin, and diabetes mellitus: observations from the SAVOR-TIMI 53 randomized trial, Circulation, 2014;130:1579-88.

41. Zannad F, Cannon CP, Cushman WC, et al., Heart failure and mortality outcomes in patients with type 2 diabetes taking alogliptin versus placebo in EXAMINE: a multicentre, randomised, double-blind trial, Lancet, 2015;385:2067-76.

42. US Food and Drug Administration. FDA drug safety communication: FDA adds warnings about heart failure risk to labels of type 2 diabetes medicines containing saxagliptin and alogliptin. Available at: www.fda.gov/Drugs/Drugsafety/ ucm486096. htm (accessed 16 April 2017).

43. Fadini GP, Avogaro A, Degli Esposti L, et al., Risk of hospitalization for heart failure in patients with type 2 diabetes newly treated with DPP-4 inhibitors or other oral glucoselowering medications: a retrospective registry study on 127,55 patients from the Nationwide OsMed Health-DB Database, Eur Heart J, 2015;36:2454-62.

44. Fadini GP, Saragoni Russo Pet al., Intraclass differences in the risk of hospitalisazion for heart failure among type 2 diabetic patients initiating a dipeptydil peptidase-4 inhibitor or a sulphonylurea. Results from the OsMed Health-DB registry, Diabetes Obes Metab. 2017:Epub date: 23 April 2017 . DOI: 10.1111/dom.12979

45. Strain W, Paldánius PM, DPP-4 inhibitor development and post-authorisation programme for vildagliptin: clinical evidence for optimised management of chronic diseases, even beyond type 2 diabetes, European Endocrinology, 2017; Accepted for publication.

46. Krum H LV, Bolli GB, et al, No significant difference in risk of heart failure hospitalization with vildagliptin in diabetic patients with systolic chronic heart failure: VIVIDD Study, Diabetes, 2014;63:A265

47. Williams R, de Vries F, Kothny W, et al., Cardiovascular safety of vildagliptin in patients with type 2 diabetes: a European multi-database, non-interventional post-authorization safety study, Diabetes Obes Metab, 2017; Epub date: 24 Mar 2017. DOI: 10.1111/dom.12951

48. Tolman KG, Fonseca V, Dalpiaz A, Tan MH, Spectrum of liver disease in type 2 diabetes and management of patients with diabetes and liver disease, Diabetes Care, 2007;30:734-43.

9. He YL, Sabo R, Campestrini J, et al., The influence of hepatic impairment on the pharmacokinetics of the dipeptidyl peptidase IV (DPP-4) inhibitor vildagliptin, Eur $J$ Clin Pharmacol, 2007;63:677-86.

50. Macauley M, Hollingsworth KG, Smith FE, et al., Effect of vildagliptin on hepatic steatosis, I Clin Endocrinol Metab 2015;100:1578-85

51. He YL, Kulmatycki K, Zhang Y, et al., Pharmacokinetics of vildagliptin in patients with varying degrees of renal impairment, Int I Clin Pharmacol Ther, 2013;51:693-703.

52. Mera J, Okada E, Okuda M, et al., Long-term efficacy of vildagliptin in patients with type 2 diabetes undergoing hemodialysis, J Diabetes Metab Disord, 2015;14:83.

53. Kothny W, Lukashevich V, Foley JE, Rendell MS, Schweizer A, Comparison of vildagliptin and sitagliptin in patients with type 2 diabetes and severe renal impairment: a randomised clinical trial, Diabetologia, 2015;58:2020-6.

54. Evans M, Dejager S, Schweizer A, Foley JE, Is there evidence of any safety differences among DPP- 4 inhibitors in the treatment of people with type 2 diabetes mellitus and reduced GFR due to chronic kidney disease?, Diabetes Ther, 2015;6:1-5.

55. Lukashevich V, Schweizer A, Foley JE, et al., Efficacy of vildagliptin in combination with insulin in patients with type 2 diabetes and severe renal impairment, Vasc Health Risk Manag, 2013;9:21-8.

56. Schweizer A, Dejager S, Experience with vildagliptin in patients $\geq 75$ years with type 2 diabetes and moderate or severe renal impairment, Diabetes Ther, 2013:4:257-67.

57. Haidinger M, Werzowa J, Hecking M, et al., Efficacy and safety of vildagliptin in new-onset diabetes after kidney transplantation-a randomized, double-blind, placebo-controlled transplantation-a randomized, double-bin
trial, Am J Transplant, 2014:14:115-23.

58. Bene J, Moulis $\mathrm{G}$, Bennani I, et al, Bullous pemphigoid and dipeptidyl peptidase IV inhibitors: a case-noncase study in the French Pharmacovigilance Database Br I Dermatol, 2016;175:296-301.

59. Garcia M, Aranburu MA, Palacios-Zabalza I, et al., Dipeptidy peptidase-IV inhibitors induced bullous pemphigoid: a case report and analysis of cases reported in the European pharmacovigilance database, I Clin Pharm Ther, 2016;41:368-70.

60. Bene J, Jacobsoone A, Coupe P, et al., Bullous pemphigoid induced by vildagliptin: a report of three cases, Fundam Clin Pharmacol, 2015;29:112-4.

61. Gudi VS, White MI, Cruickshank N, et al., Annual incidence and mortality of bullous pemphigoid in the Grampian Region of North-east Scotland, Br J Dermatol, 2005:153:424-7.

62. Langan SM, Smeeth L, Hubbard R, et al., Bullous pemphigoid and pemphigus vulgaris-incidence and mortality in the UK: population based cohort study, BMJ, 2008:337:151-63.

63. Joly P, Baricault S, Sparsa A, et al., Incidence and mortality of bullous pemphigoid in France, I Invest Dermatol, 2012;132:1998-2004

64. Mascolo A, Rafaniello C, Sportiello L, et al., Dipeptidyl Peptidase (DPP)-4 Inhibitor-Induced Arthritis/Arthralgia: A Review of Clinical Cases, Drug Saf, 2016;39:401-7.

65. US Food and Drug Administration. FDA drug safety communication: FDA warns that DPP-4 inhibitors for type 2 diabetes may cause severe joint pain. Available at: www.fda gov/ Drugs/DrugSafety/ucm459579.htm (accessed 16 April 2017). 